\title{
Pakistan: Joint Staff Assessment of Poverty Reduction Strategy Paper Progress Report
}

The attached Joint Staff Assessment (JSA) of the Poverty Reduction Strategy Paper Progress Report for Pakistan, prepared by the staffs of both the World Bank and IMF, was submitted with the member country's Poverty Reduction Strategy Paper (PRSP) or Interim PRSP (IPRSP) to the Executive Boards of the two institutions. A JSA evaluates the strengths and weaknesses of a country's poverty reduction objectives and strategies, and considers whether the PRSP or IPRSP provides a sound basis for concessional assistance from the Bank and Fund, as well as for debt relief under the Enhanced Heavily Indebted Poor Countries (HIPC) Debt Initiative. The Boards then decide whether the poverty reduction strategy merits such support.

To assist the IMF in evaluating the publication policy, reader comments are invited and may be sent by e-mail to publicationpolicy@imf.org.

Copies of this report are available to the public from

International Monetary Fund • Publication Services

$70019^{\text {th }}$ Street, N.W. $\bullet$ Washington, D.C. 20431

Telephone: (202) 623-7430 • Telefax: (202) 623-7201

E-mail: publications@imf.org・Internet: http://www.imf.org

\section{International Monetary Fund Washington, D.C.}




\title{
INTERNATIONAL MONETARY FUND \\ AND THE INTERNATIONAL DEVELOPMENT ASSOCIATION
}

\author{
PAKISTAN \\ Joint Staff Assessment of the \\ Poverty Reduction Strategy Paper Preparation Status Report
}

\author{
Prepared by the Staffs of the International Monetary Fund \\ and the International Development Association \\ Approved by George T. Abed and Michael T. Hadjimichael (IMF) and \\ Mieko Nishimizu and Gobind Nankani (IDA)
}

January 31,2003

1. The Pakistani authorities presented to the Executive Boards of the IDA and the IMF in December 2001 the interim Poverty Reduction Strategy Paper (I-PRSP). The Boards agreed that the document provided a sound basis for the development of a fully participatory Poverty Reduction Strategy Paper (PRSP). At that time, the full PRSP was expected to be finalized by January 2003 following elections and the formation of a civilian government. Elections were held as planned but with no party gaining an absolute majority, formation of new governments at both the national and provincial levels was delayed. Consequently the Government of Pakistan has decided to delay preparation of the full PRSP until April, 2003. Given the importance of ensuring full ownership of the PRSP by the new government, the staffs of the World Bank and the Fund support this decision. As the PRSP will not be finished within one year of the completion of the I-PRSP, the authorities have issued a Preparation Status Report for presentation to the Boards of the World Bank and IMF. The report outlines the main activities undertaken, next steps, and a revised timeline for preparation of the full PRSP.

2. The Joint Staff Assessment (JSA) of the I-PRSP identified some important gaps in the poverty reduction strategy for Pakistan. These included the following: a detailed rural development strategy; a more focused human development strategy; a coherent fiscal framework taking into account mechanisms for transfer of resources and responsibilities from federal and provincial governments to the district governments (in the context of the ongoing devolution exercise); costing of programs to achieve targets, particularly in the health and education sector; and a monitoring framework - particularly for tracking intermediate indicators in the social sectors and anti poverty programs. The preparation status report emphasizes the government's commitment to continuity of the reforms envisaged in the I-PRSP and outlines various aspects of the process, timeline, content, and progress along these dimensions.

3. Country Ownership and Participation. The I-PRSP outlined key processes to be set in motion to ensure full participation in formulation of the PRSP, including at the provincial level and by the newly elected district officials and civil society. The Government of Pakistan launched a PRSP-type process to ensure full consultation at the level of provinces and districts. This process came to a halt as the new government was being installed following the national elections in October 2002. The preparation status report outlines a new timeline for getting 
inputs from the provinces. The authorities report that the participatory process is fully engaged at the provincial level, with a number of seminars and workshops for consultations in the provinces being conducted or planned, which should be strengthened with more extensive community level discussions. The timeline outlined in the report reflects the latter, through activities like consultation with stakeholders by provinces and with communities through the Rural Support Program network. Among the provinces, it appears that North West Frontier Province (NWFP), Sindh, and Balochistan are ahead of Punjab where a majority of the population of Pakistan resides. While this marks encouraging progress, ensuring full participation of Punjab is critical. In line with the restoration of democratically elected government, the staffs believe it would also be useful to encourage wider public discussion through, for example, media mediated debates or other forums including the newly formed parliament, in addition to placing the document on the web as the authorities plan according to the preparation status report.

4. Poverty Diagnostics. The I-PRSP presented the poverty diagnostics though 1998-99. In the meantime the 2000-01 round of the Pakistan Integrated Household Survey has been completed. Recent discussions around this issue point to concerns of the government of Paksitan on methodology and data quality, and a committee is being set up to assess these concerns. The staffs have been assured that there will be quick resolution of this matter and expect that the full PRSP will update the diagnostics along important dimensions of poverty measurement (outlining the methodology of the newly adopted official poverty line) and social indicators with necessary disaggregation to portray the rural-urban and other regional dimensions and link these insights into refinements of the core policy priorities.

5. Development of the Full PRSP. The preparation status report highlights and endorses the policy agenda outlined in the I-PRSP. Key issues include:

(i) Macro economic Framework. Although not elaborated in the preparation status report, recent developments indicate further progress towards macroeconomic stabilization, in line with the I-PRSP framework. The continuation of sound macroeconomic and structural policies has contributed to a significant improvement of the external and fiscal positions and a pick-up in growth. The authorities have pursued an ambitious tax administration reform agenda that appears to have started bearing fruit. However, lack of significant improvements in the performance of some public sector enterprises, notably in the power sector, is imposing a serious drain on public finances. The staffs recommend that the authorities monitor carefully these macroeconomic developments and to develop perhaps 2 different macroeconomic scenarios in the PRSP, including a cautious baseline scenario and a more optimistic one reflecting a rapid implementation and impact of economic reform.

(ii) Sectoral Policy Agenda. First, while the increase in poverty-related expenditures as reported in the preparation status report is a positive development, the staffs recommend the full PRSP forcefully address implementation problems at the local level. With devolution, responsibility for service delivery (health, education, water, and community infrastructure) rests with the newly formed district governments and rationalization of the roles and responsibilities of the three tiers of government-federal, provincial, and district-is a critical component of effective devolution. The preparation status report outlines establishment of provincial finance commissions, as well as the additional federal transfers envisaged, but further work is needed to define mechanisms for adequate 
costing and governance structures to ensure accountability. The full PRSP should also address the challenge of capacity building at the district level in planning and budgeting, as well as revenue raising mechanisms. Second, rural development is a priority area for a poverty reduction strategy in Pakistan and the JSA identified this as a key area for deepening policy and action. The preparation status report views the rural strategy through the lens of the provincial agenda in the newly devolved environment and expects the strategy to emerge from provincial inputs for the full PRSP. However, other key challenges in the sector including improving access to land and other assets by the landless lie within the federal ambit; a discussion of these broader challenges is important as highlighted in the I-PRSP and the JSA. Lastly, the growth strategy envisaged could be strengthened by identifying the sources of growth and making the links between growth, employment and poverty, to examine the key factors that would translate into poverty reduction. For example, stagnancy in rural poverty suggests a lack of progress in enhancing rural productivity.

(iii) Gaps identified in the Interim-PRSP. The Status report highlights the gaps in the IPRSP, and identifies areas the full PRSP will likely address, drawing on inputs from a number of sources, including analytical work and surveys conducted by various donors. However, given the limited time, it may be useful to prioritize the areas that can be addressed by the PRSP. In the staffs' view, the first areas of priority are costing of reforms and pro-poor programs and financing and resource gap. In this context, the inclusion of medium term costing of the health and education sectors in the full PRSPmentioned in the status report-will be a significant step

6. Institutional Arrangements. The PRSP Preparation Status report extensively highlights the institutional arrangements for the implementation of the full PRSP. The government had set up a PRSP Secretariat during the preparation of Interim-PRSP, and this has since been strengthened in a number of ways. This includes setting up a National Steering Committee headed by the Finance Secretary with high level representation of relevant Ministries, institutions and provinces, and the appointment of a high level official as the focal person in the PRSP Secretariat, reporting directly to the Finance Secretary and the Finance Minister. The staffs view these as positive steps-likely to improve the clarity of responsibility for implementing the process, the coordination among all implementing agencies, and the process of building consensus among all stakeholders like the provinces and civil society institutions.

7. Monitoring and Evaluation. The preparation status report highlights progress in expenditure tracking and the government has been publishing quarterly reports presenting PRSPrelated expenditures. There has been significant progress on the monitoring of public expenditures. A whole new system has been set up to monitor expenditures at the local level, and these are now being reported on a quarterly basis for the first time ever. However, there is a concern that expenditure reporting may not be fully comparable between the different provinces. The authorities have rightly put great emphasis on increasing social and poverty-related spending while devolving spending responsibility to local governments. At the same time, continued implementation problems at the local level result largely from capacity bottlenecks and continued 'teething' problems with devolution. The full PRSP will need to pay close attention to these implementation problems, as well as expenditure tracking, ensuring comparability across provinces, to achieve adequate and high quality social service delivery. 
8. On poverty monitoring, further progress is needed in implementation. The I-PRSP has a well designed framework, but challenges remain in the areas of implementing independent monitoring of outcomes and intermediate indicators. The Government's quarterly PRSP reporting has included information on several health and education intermediate indicators, including benchmarks for four of them. Additional intermediate indicators have been selected through a thorough consultation process, which has ensured broad consensus among relevant ministries, provinces and institutions about their appropriateness to track the impact of reforms in social sectors and provide feedback to policymakers. The process has also ensured that the indicators chosen are consistent with the Millennium Development Goals, tailored to the local context of Pakistan. In the staff's view, a well-focused annual Core Welfare Indicators Questionnaire (CWIQ) like the ones fielded in many African countries could be a highly useful supplement to and cross-check of the data reported through the traditional administrative reporting channel. The latter may indeed be biased toward reporting "success" and in some cases measure only the quality of the public service delivery, whereas social outcomes are also influenced by private service providers (providing about 40 percent of education and health services). However, implementation arrangements for a CWIQ are not detailed in the preparation status report. With respect to poverty outcomes and human development, the authorities will need to rapidly address the technical concerns regarding the Pakistan Integrated Household Survey in order to establish the credible baselines needed for costing the interventions needed to achieve health, education and other PRSP targets. Finally, the Federal Bureau of Statistics, the institution that designs and collects poverty monitoring data, needs greater autonomy and capacity-building support in order to effectively carry out this responsibility. The staffs look forward to elaboration of these issues in the PRSP.

9. In light of the scope of preparatory work still needed, and the need to ensure broad public consultation, the timeline for finalization of the full PRSP is ambitious, although achievable. The staffs consider it of utmost importance that it should not harm the quality of the PRSP. Having said that, extensive discussions with the government have revealed that in order to maintain the momentum of the reform process, the government would like to adhere to this timeline. The staffs agree with the need to retain the momentum of reforms, for which the pace of the PRSP process will be critical.

\section{Risks and Outlook}

10. The JSA of the I-PRSP identified four risks to implementation: political opposition to reforms; lack of continuity; insufficient institutional capacity; and exogenous shocks. While these risks are still prevalent, their relative importance has shifted. The authorities have made significant progress in implementing the agenda set out in the I-PRSP. While some of the measures taken, for example the gas prices increases, were highly unpopular, they were implemented in the end. The government's efforts at communicating the content and rationale of such difficult measures was an integral part of the implementation process, although much more needs to be done. Continuation of such open communication should further help in carrying forward the reform agenda. The new government has clearly stated its commitments to the PRSP policy content and process. There is substantial continuity of the economic team of the cabinet. However, with the government holding only a small majority in parliament, reforms could slow down due to the need to build consensus in the coalition government and Parliament. In particular, building support in Parliament for the devolution initiative will be important for ensuring its success. Insufficient institutional capacity continues to be a problem, even though 
some progress has been made since the I-PRSP. The authorities will need to intensify their efforts in this respect to ensure that the reforms translate into tangible improvements for the people and the poor in particular. Lastly, exogenous shocks still constitute a significant risk. Slower than expected winding down of regional tensions or a possible conflict in the Middle East could adversely effect growth and fiscal projections.

11. In sum, the staffs of the World Bank and the IMF consider that progress on the development of the full PRSP, as evidenced by the PRSP Preparation Status Report, is satisfactory, especially given the dramatic political transition, and provides a basis for continued access to IDA adjustment lending and Fund concessional financial assistance. The staffs recommend that the Executive Directors of the World Bank and IMF reach the same conclusion. 